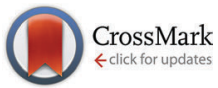

Cite this: J. Mater. Chem. C, 2016 , 4, 10090

Received 20th September 2016, Accepted 9th October 2016

DOI: $10.1039 / c 6 t c 04112 d$

www.rsc.org/MaterialsC

\section{Solution processable neutral state colourless electrochromic devices: effect of the layer thickness on the electrochromic performance $\dagger$}

\author{
Gurhan Tahtali, ${ }^{a}$ Zeynep Has, ${ }^{b}$ Ceylan Doyranli, ${ }^{c}$ Canan Varlikli ${ }^{d}$ and \\ Sermet Koyuncu*bce
}

\begin{abstract}
In this study, a neutral state colourless electrochromic device fabricated through a solution process is introduced. The device contains indium doped transparent oxide coated glass as the transparent conductive electrode, poly( $N$-(2-ethylhexyl)carbazol-3,6-diyl) (PCbz) as the anodically colouring material, poly(3,4-ethylenedioxythiophene):poly(styrenesulfonate) (PEDOT:PSS) as the ion storage layer and a lithium perchlorate based conducting gel electrolyte. A maximum optical contrast $(\Delta T \%)$ of $58 \%$ at $800 \mathrm{~nm}$ is achieved by optimizing the film thickness of both the organic layers. The device that has layers of $220 \mathrm{~nm}$ PCbz and $120 \mathrm{~nm}$ PEDOT:PSS thickness revealed a high coloration efficiency $\left(1246 \mathrm{~cm}^{2} \mathrm{C}^{-1}\right)$ and colouring and bleaching response times of $5.6 \mathrm{~s}$ and $2.3 \mathrm{~s}$, respectively.
\end{abstract}

\section{Introduction}

Electrochromic materials are capable of changing colour and consequently transmittance under applied potential. ${ }^{1}$ These materials are used in different technological applications, such as anti-glare rear-view mirrors, ${ }^{2}$ electrochromic displays, ${ }^{3,4}$ earth tone chameleon materials, ${ }^{5}$ and smart windows for buildings or cars. ${ }^{6,7}$ The first applications of electrochromic materials started with semiconductors based on inorganic materials such as $\mathrm{IrO}_{2}$ and $\mathrm{WO}_{3}{ }^{8-10}$ and then continued with organic small molecules based on viologens. ${ }^{11-14}$ Finally, conjugated polymers have gained quite an importance over the course of time ${ }^{15}$ owing to their superior features of tunable HOMO-LUMO band gap and also potential application in low-cost, large-area flexible devices.

Upon their oxidation process, all neutral state RGB or CMYK electrochromic materials can be converted to a colourless and transmissive state. ${ }^{16}$ In other words, common electrochromic materials must be continuously retained in their oxidized state, which requires consumption of energy and may cause degradation of the electrochromic material in order to gain transparency when needed. Band gap control is the most important issue for

\footnotetext{
${ }^{a}$ Ege University, Solar Energy Institute, 35040 Bornova, Izmir, Turkey

${ }^{b}$ Department of Energy Resources and Development, Çanakkale Onsekiz Mart University, 17020 Çanakkale, Turkey

${ }^{c}$ Polymeric Materials Research Laboratory, Çanakkale Onsekiz Mart University, 17100, Çanakkale, Turkey

${ }^{d}$ Department of Photonics, Izmir Institute of Technology, 35430 Urla-Izmir, Turkey

${ }^{e}$ Department of Chemical Engineering, Faculty of Engineering, Canakkale Onsekiz Mart University, 17020, Canakkale,Turkey.E-mail: skoyuncu@comu.edu.tr

$\dagger$ Electronic supplementary information (ESI) available. See DOI: 10.1039/c6tc04112d
}

electrochromic materials to arrange a neutral state colour. ${ }^{15}$ Among electrochromic polymers, poly(3,6-carbazole) is known to be an effective short wavelength emitter and also an electrondonating (p-type) chromophore. ${ }^{17}$ The neutral state colourless property of poly(3,6-carbazole) allows its utilization in electrochromic devices such as smart windows. ${ }^{18-22}$

Electrochromic devices (ECDs) are typically multi-layered sandwich structures containing several interfaces that command the eventual device performance metrics, such as stability, coloration efficiency and response time in switching between high transmittance (bleached) and low transmittance (coloured) states. ${ }^{23-25}$ ECDs composed of electrochromic materials, which allow the switching of colours between neutral and oxidized/ reduced states, have been extensively studied. ${ }^{26-28}$ In order for ECDs to be commercialized, a short response time, long-term cyclic stability, high coloration efficiency (CE), large optical modulation, high initial transparency and low cost are essential requirements.

In this work, a solution processed complementary electrochromic device is introduced with the use of indium doped transparent oxide (ITO) coated glass as the transparent conductive electrode, poly( $N$-(2-ethylhexyl)carbazol-3,6-diyl) (PCbz) as the anodically colouring material, poly(3,4-ethylenedioxythiophene): poly(styrenesulfonate) (PEDOT:PSS) as the ion storage layer and lithium perchlorate-polymethylmethacrylate $\left(\mathrm{LiClO}_{4}-\mathrm{PMMA}\right)$ matrix as the gel electrolyte. The effect of film thickness of both the organic layers on the ECD performance is discussed. The PCbz polymer film on the ITO/glass surface has an optical transmittance value of $>95 \%$ in the visible and near-infrared (NIR) regime in the neutral state. When the thickness of the 


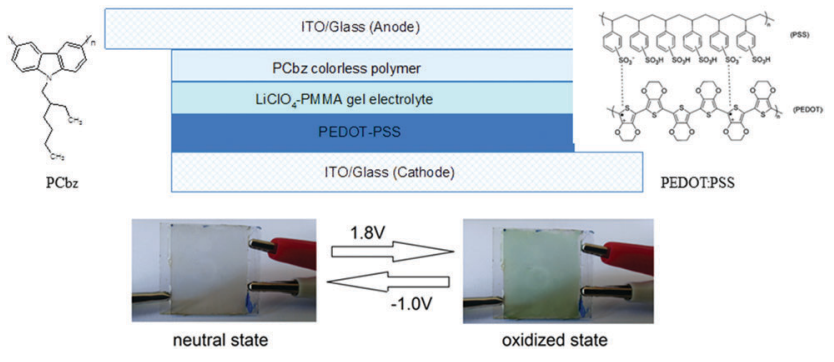

Fig. 1 Neutral state colourless/transmissive PCbz/PEDOT:PSS based electrochromic device structure.

PEDOT:PSS and PCbz films are 440, 325, 220 and $180 \mathrm{~nm}$, the prepared colourless and highly transmissive ECDs can be driven between -1.0 and $1.8 \mathrm{~V}$ (Fig. 1), giving high coloration efficiencies between 921 and $1684 \mathrm{~cm}^{2} \mathrm{C}^{-1}$, high redox stability and reasonable response times (about $5 \mathrm{~s}$ ). In summary, it is very clear that PCbz based polymers can be counted as a capable material to be used in large area smart window applications in electrochromic technology due to this important behaviour. ${ }^{29}$

\section{Results and discussion}

\section{Spectroelectrochemical measurements}

The PCbz polymer was synthesized in 3 steps $^{17}$ (see Scheme S1, ESI $\dagger$ ) and then the polymer films were prepared via a spin coating process. Oxidative spectroelectrochemistry was carried out on the polymeric film of PCbz on an ITO/glass surface in order to clarify its electrochromic behaviour upon p-doping. In the neutral state, the polymer only absorbs the UV regime corresponding to a transparent and colourless film. Upon a positive scan from 0 to $1.8 \mathrm{~V}$, the bands centred at about $405 \mathrm{~nm}$ and $900 \mathrm{~nm}$ intensified at the same time, indicating the formation of polarons and bipolarons on the PCbz film surface (Fig. 2). Owing to two new bands occurring in the blue and red regimes, the colourless and transparent PCbz film $\left(L^{*}: 88 ; a:-1 ; b:-3\right)$ in the neutral state, corresponding to no absorption in the visible regime, is turned to green $\left(L^{*}: 57\right.$;

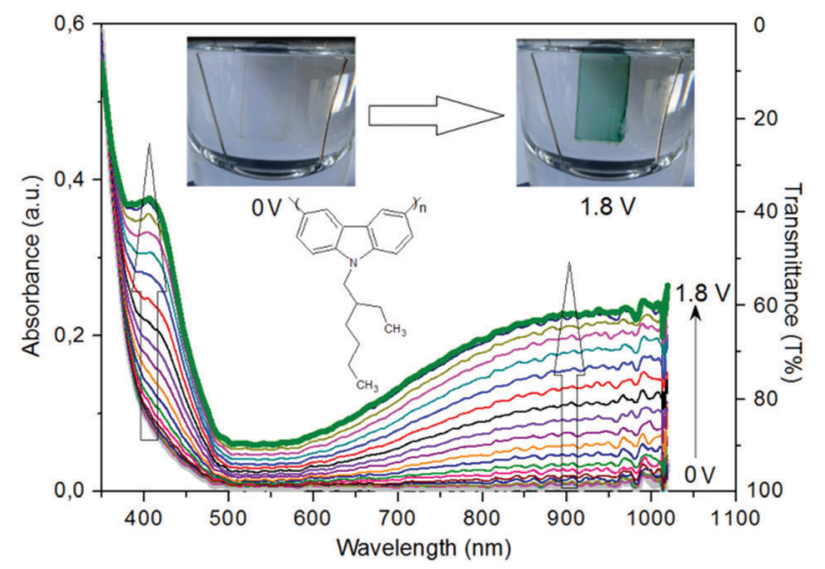

Fig. 2 Electronic absorption spectra and colour changes of PCbz on ITO/glass surface in $0.1 \mathrm{M} \mathrm{LiClO} / 4 / \mathrm{CH}_{3} \mathrm{CN}$ between 0 and $1.8 \mathrm{~V}$. $a:-31 ; b: 4)$. Within the applied potential range, 40 to $50 \%$ of the maximum transmittance change $(\Delta T \%)$ was observed in both the near-IR and UV regimes.

\section{PCbz/PEDOT:PSS electrochromic device}

ECDs based on the neutral state colourless polymer PCbz were prepared with a sandwich configuration (Fig. 1). It is known from the literature that an optimal thickness corresponding to the maximum transmittance change exists for each electrochromic polymer. $^{30,31}$ Therefore, the film thickness of the PEDOT:PSS and PCbz layers on the ITO coated glass were varied by applying two different spinning rates and measured to be 120 and $170 \mathrm{~nm}$, and 180, 220, 325 and $440 \mathrm{~nm}$, respectively. In addition, the maximum RMS (root mean surface) roughness for different thickness PCbz films was observed to be about 32, 35, 52 and $61 \mathrm{~nm}$, corresponding to a rough film surface. The roughness values of the coatings were quite high, which was attributed to spikes on the ITO surface ${ }^{32}$ (Fig. 3). Six ECDs in which the film thickness of the PEDOT:PSS and PCbz layers on the ITO substrates changed were fabricated. The devices where the PEDOT:PSS thickness was $120 \mathrm{~nm}$ and PCbz thickness was 180, 220 and $325 \mathrm{~nm}$, and where the PEDOT:PSS thickness was $170 \mathrm{~nm}$ and PCbz thickness was again 220, 325 and $440 \mathrm{~nm}$ were labelled as ECD-1, 2, 3, 4, 5 and 6, respectively. The active area of the ECDs was $5 \mathrm{~cm}^{2}(2 \mathrm{~cm} \times 2.5 \mathrm{~cm})$. The ECD performance data are summarized in Table 1.

The optical responses of the PCbz/PEDOT devices upon applying potentials between -1.0 and $1.8 \mathrm{~V}$ were investigated (Fig. 3 and Fig. S11-S15, ESI $\dagger$ ). During the coloration process, PCbz was oxidized and the PEDOT:PSS layer was reduced simultaneously. In the initial state $(-1.0 \mathrm{~V})$, the ECDs were nearly transparent and colourless $\left(L^{*}: 87 ; a:-2 ; b:-3\right)$ due to the fact that the PEDOT:PSS and PCbz layers do not absorb visible light. Upon increasing the applied potential, due to the simultaneous oxidation of $\mathbf{P C b z}$ and reduction of the PEDOT:PSS layers, the bands at about $420 \mathrm{~nm}$ and $810 \mathrm{~nm}$ are intensified. Those devices prepared using thicker films (devices 2, 3, 4 and 6) presented a new band formation with

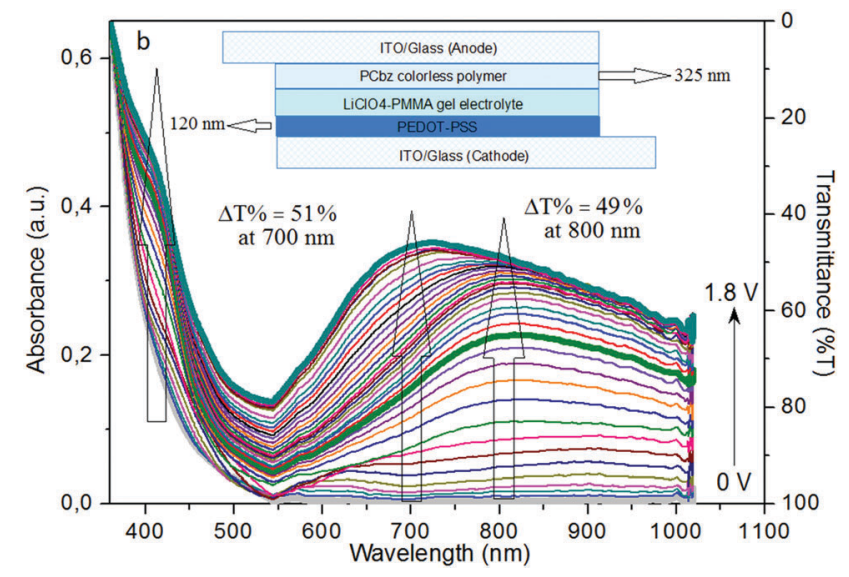

Fig. 3 Spectroelectrochemical measurements of a PCbz/PEDOT:PSS device (ECD-2). 
Table 1 Electrochromic parameters for the PCbz/PEDOT-PSS based ECDs

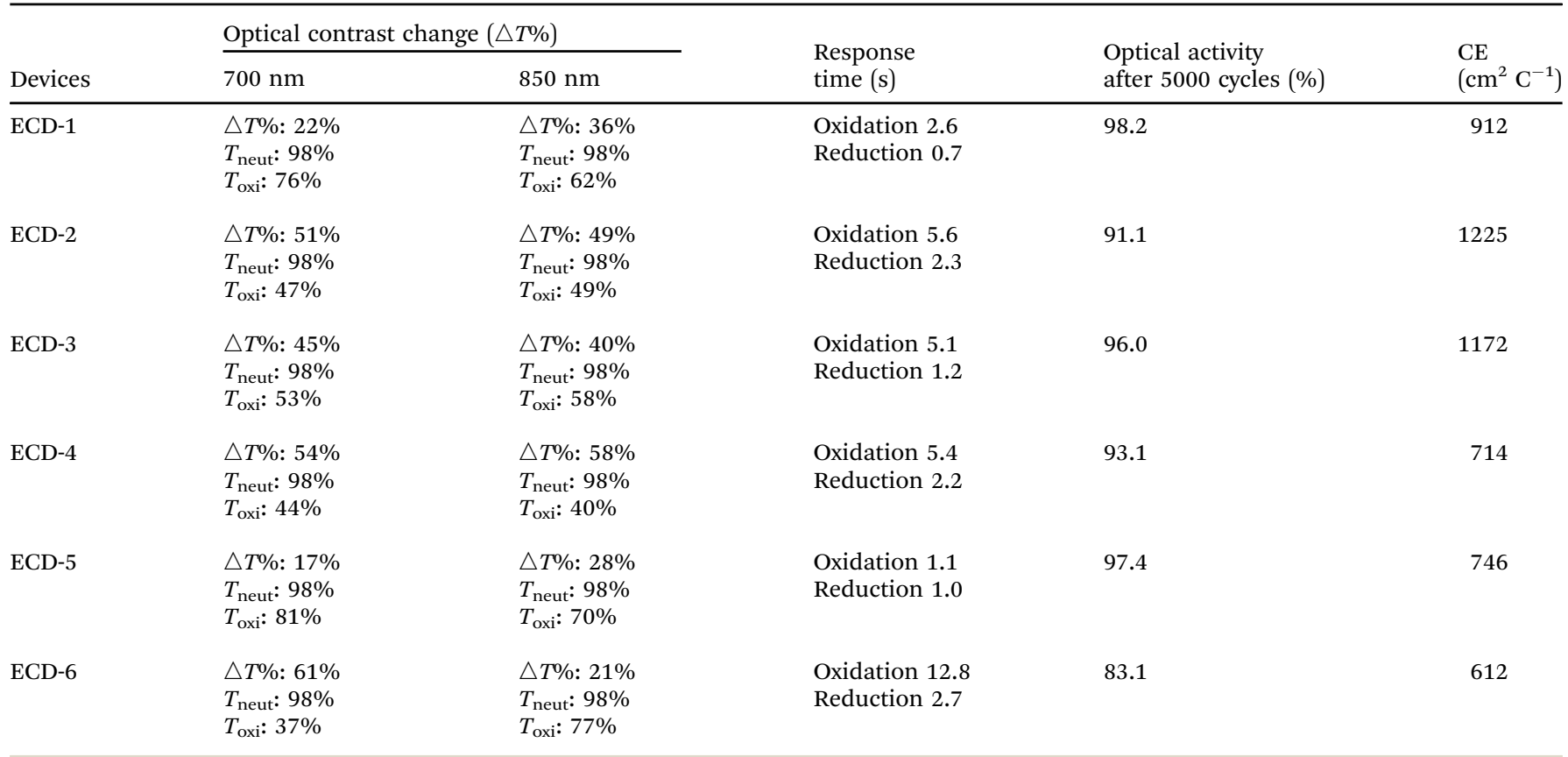

an applied potential $>1.3 \mathrm{~V}$ at around $700 \mathrm{~nm}$ (Fig. 3 and Fig. S12, S13 and S15, ESI $\dagger$ ). As the spectral signatures of PCbz and the PEDOT:PSS layer became dominant, the ECD colour turned to green $\left(L^{*}: 48 ; a:-26 ; b: 8\right)$ and blue $\left(L^{*}: 44 ; a:-22\right.$; $b:-8$ ), respectively (Fig. 3 ).

A double step chronoamperometry technique was used to monitor the changes in the electro-optical response during electrochemical switching of the ECDs (Fig. 4). Electrochromic parameters of the ECDs were examined from the variations that occurred in the transmittance (increasing and decreasing of the absorption bands at $800 \mathrm{~nm}$ according to time) while exchanging the voltage between -1.0 and $1.8 \mathrm{~V}$ with a $10 \mathrm{~s}$ period. It was observed that $\Delta T \%$ at $800 \mathrm{~nm}$ improved from $28 \%$ to $58 \%$ upon increasing the thickness of both the PEDOT:PSS and PCbz layers.

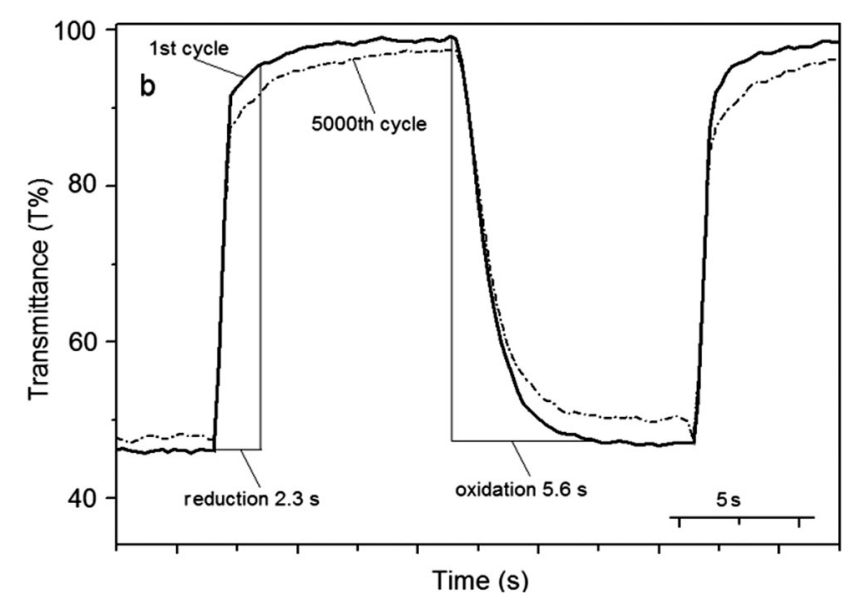

Fig. 4 Electrochromic switching and optical absorbance monitored at $800 \mathrm{~nm}$ for a PCbz/PEDOT:PSS based device (ECD-2) between -1.0 and $1.8 \mathrm{~V}$.
On the other hand, 51,54 and $61 \%$ of $\Delta T \%$ were obtained from ECD-2, ECD-4 and ECD-6 in the visible regime (at 650 and $700 \mathrm{~nm}$ ). The colouring and bleaching response times of the ECDs were, respectively, calculated as $0.7 \mathrm{~s}$ and $2.6 \mathrm{~s}$ for ECD-1, 2.3 and $5.6 \mathrm{~s}$ for ECD-2, $1.2 \mathrm{~s}$ and $5.1 \mathrm{~s}$ for ECD-3, $2.2 \mathrm{~s}$ and $5.4 \mathrm{~s}$ for ECD-4, $1.1 \mathrm{~s}$ and $1.0 \mathrm{~s}$ for ECD-5, and $2.7 \mathrm{~s}$ and $12.8 \mathrm{~s}$ for ECD-6. After 5000 cycles of operation with a $10 \mathrm{~s}$ period, it was observed that all ECDs preserved their optical activity above $90 \%$ apart from ECD-6. It can be clearly seen that $\Delta T \%$ of ECD-2, ECD-4 and ECD-6, which contain a thicker PCbz polymer film, are better than those of ECD-1, ECD-3 and ECD-5. These electrooptical results also suggest that they have very strong redox stabilities and reasonable response times. On the other hand, the coloration efficiency (CE) is one of the most significant parameters for electrochromic application. ${ }^{33}$ The $\mathrm{CE}$ was calculated using the equations $\mathrm{CE}=\Delta \mathrm{OD} / Q_{\mathrm{d}}$ and $\Delta \mathrm{OD}=\log \left(T_{\text {coloured }} / T_{\text {bleached }}\right)$, where $Q_{\mathrm{d}}$ is the injected/ejected charge between neutral and oxidized states, and $T_{\text {coloured }}$ and $T_{\text {bleached }}$ are the transmittance in the oxidized and neutral states, respectively. The CE values of ECD-1-6 were calculated to be $912 \mathrm{~cm}^{2} \mathrm{C}^{-1}, 1225 \mathrm{~cm}^{2} \mathrm{C}^{-1}$, $1172 \mathrm{~cm}^{2} \mathrm{C}^{-1}, 714 \mathrm{~cm}^{2} \mathrm{C}^{-1}, 746 \mathrm{~cm}^{2} \mathrm{C}^{-1}$ and $612 \mathrm{~cm}^{2} \mathrm{C}^{-1}$, respectively. The CE value obtained from ECD-4 is one of the highest values for carbazole based electrochromic devices reported in the literature. ${ }^{18,34-38}$

\section{Conclusion}

Herein, the effect of the layer thickness on the electrochromic performance of neutral state colourless ECDs constructed with a sandwich structure of ITO/poly-(PC)//gel electrolyte//PEDOT/ ITO was investigated. The colourless ECDs in the neutral state converted to dark green on applying $1.8 \mathrm{~V}$. A maximum optical 
contrast $(\Delta T \%)$ was obtained around $58 \%$ at $800 \mathrm{~nm}$ owing to the arrangement of the film thickness and roughness of the both layers to optimize the electrochromic performance of the ECDs. It was observed that a rougher and more porous PCbz layer improved the response time and optical contrast $(\Delta T \%)$ through the advantage of facilitating ion diffusion across the PCbz and PEDOT layers. The PCbz based electrochromic material can be counted as favourable for use in large area and low cost smart window applications due to its solution processability and neutral state colourless and highly transmissive properties.

\section{Experimental section}

Synthetic and structural optical and electrochemical characterization of PCbz is given in the ESI $\dagger$ (see Fig. S1-S4). On the ITO/glass surface, the polymer was spin-coated using $2 \mathrm{wt} \%$ chlorobenzene (CB) of PCbz polymer with different spin rates. The layer thickness was measured using an Ambios Tech XP-1 high resolution profilometer. On the other hand, the polymer coated ITO/glass electrodes were scanned with an Ambios Qscope 250 and Nanosurf Naio model Atomic Force Microscope (AFM) over a $10 \mu \mathrm{m} \times 10 \mu \mathrm{m}$ measurement area. To obtain the topographic image, AFM measurements were carried out in non-contact mode (wave mode) at ambient conditions and room temperature. A $10 \mathrm{~nm}$ tip-curvature and $20 \mu \mathrm{m}$ scanner equipped with silicon tips were used. The AFM system was covered with an acoustic chamber to prevent electromagnetic noise.

Spectroelectrochemical measurements were carried out to obtain the absorption spectra of the polymer films upon applying the potential using an electrochemical workstation. ${ }^{39}$ The spectroelectrochemical cell includes a quartz cuvette, an Ag wire (RE), Pt wire counter electrode (CE) and ITO/glass as the transparent working electrode (WE). These measurements were carried out in $0.1 \mathrm{M} \mathrm{LiClO}_{4}$ as supporting electrolyte in $\mathrm{CH}_{3} \mathrm{CN}$.

The electrochromic devices (ECDs) were fabricated on indium tin oxide (ITO) covered glass substrates with a sandwich configuration of ITO/PCbz (180, 220, 325 and $440 \mathrm{~nm}) / /$ gel electrolyte//PEDOT-PSS (120 and $170 \mathrm{~nm}$ )/ITO. First, ITO/glass electrodes were cleaned with detergent, deionized water, acetone and isopropanol and then oven-dried at $100{ }^{\circ} \mathrm{C}$ for $5 \mathrm{~h}$, and finally treated with oxygen plasma. Two different thicknesses (120 and $170 \mathrm{~nm}$ ) of PEDOTPSS was spin-coated from aqueous solution (Baytron PH500, HC Stack Inc) onto the ITO/glass surface $\left(5 \mathrm{~cm}^{2}\right)$. The coated PEDOT-PSS films were dried for $10 \mathrm{~min}$. at $150{ }^{\circ} \mathrm{C}$. The PCbz films were prepared using a spin casting process with different spin rates onto another ITO/glass substrate. The polymer films were annealed at $120{ }^{\circ} \mathrm{C}$ for $30 \mathrm{~min}$. The gel electrolyte was prepared from $\mathrm{LiClO}_{4} / \mathrm{ACN} /$ poly (methylmethacrylate) (PMMA, $\left.M_{\mathrm{w}}: 15000\right) / 1,2$-propylenecarbonate in a ratio of $3: 70: 7: 20$ by weight. Just after dissolution of $\mathrm{LiClO}_{4}$ in acetonitrile, PMMA was plasticized by adding PC to form a highly transparent and conductive gel. The gel electrolyte was spread over the face of each coated substrate (both PEDOT-PSS and PCbz polymers). Finally, individual ITO/glass layers were stacked face-to-face. ${ }^{33}$
Colorimetry measurements were carried out for the neutral and oxidized states of the ECDs. These measurements were performed by using an Analytic Jena Specord S600 UV-Vis spectrophotometer which contains a chromometer module. In the CIE colour measurement system, the colour was measured using three characteristics: luminance $(L)$, hue $(a)$, and saturation $(b){ }^{40}$ Gardner DIN ISO 6430, platinum cobalt DIN ISO 621, and iodine DIN EN 1557 were used as references for these measurements.

\section{Acknowledgements}

S. Koyuncu is grateful to Canakkale Onsekiz Mart University Research Funds Office (Project \#: COMU-BAP 2015/513) for financial support.

\section{References}

1 H. Witzke and S. K. Deb, Am. Ceram. Soc. Bull., 1977, 56, 321-322. 2 T. Luchetti, A. Zanella, M. Biasiotto and A. Saccagno, J. Mater. Eng. Perform., 2009, 18, 717-724.

3 D. R. Rosseinsky and R. J. Mortimer, Adv. Mater., 2001, 13, 783-793.

4 R. J. Mortimer, A. L. Dyer and J. R. Reynolds, Displays, 2006, 27, 2-18.

5 B. C. Thompson, P. Schottland, K. W. Zong and J. R. Reynolds, Chem. Mater., 2000, 12, 1563-1571.

6 R. D. Rauh, Electrochim. Acta, 1999, 44, 3165-3176.

7 R. Baetens, B. P. Jelle and A. Gustavsen, Sol. Energy Mater. Sol. Cells, 2010, 94, 87-105.

8 C. G. Granqvist, Solid State Ionics, 1992, 53, 479-489.

9 A. Azens, G. Vaivars, L. Kullman and C. G. Granqvist, Electrochim. Acta, 1999, 44, 3059-3061.

10 C. G. Granqvist, Electrochim. Acta, 1999, 44, 3005-3015.

11 R. Cinnsealach, G. Boschloo, S. N. Rao and D. Fitzmaurice, Sol. Energy Mater. Sol. Cells, 1998, 55, 215-223.

12 P. M. S. Monk, J. Electroanal. Chem., 1997, 432, 175-179.

13 A. Yasuda, M. Itabashi, H. Kondo, H. Mori and J. Seto, Proc. SID, 1987, 28, 239-242.

14 A. Yasuda and J. Seto, J. Electroanal. Chem., 1990, 283, 197-204.

15 P. M. Beaujuge and J. R. Reynolds, Chem. Rev., 2010, 110, 268-320.

16 C. M. Amb, A. L. Dyer and J. R. Reynolds, Chem. Mater., 2011, 23, 397-415.

17 Z. B. Zhang, M. Fujiki, H. Z. Tang, M. Motonaga and K. Torimitsu, Macromolecules, 2002, 35, 1988-1990.

18 O. Usluer, S. Koyuncu, S. Demic and R. A. J. Janssen, J. Polym. Sci., Part B: Polym. Phys., 2011, 49, 333-341.

19 S. H. Hsiao, H. M. Wang, J. W. Lin, W. J. Guo, Y. R. Kung, C. M. Leu and T. M. Lee, Mater. Chem. Phys., 2013, 141, 665-673.

20 G. S. Liou, H. W. Chen and H. J. Yen, Macromol. Chem. Phys., 2006, 207, 1589-1598.

21 G. S. Liou, S. H. Hsiao and H. W. Chen, J. Mater. Chem., 2006, 16, 1831-1842.

22 H. J. Yen, C. J. Chen and G. S. Liou, Adv. Funct. Mater., 2013, 23, 5307-5316. 
23 H. Witzke and S. K. Deb, J. Electrochem. Soc., 1976, 123, C258-C258.

24 C. M. Lampert, Sol. Energy Mater., 1984, 11, 1-27.

25 P. R. Somani and S. Radhakrishnan, Mater. Chem. Phys., 2003, 77, 117-133.

26 S. Hara, H. Shiozaki, A. Omura, H. Tanaka, T. Kawamoto, M. Tokumoto, M. Yamada, A. Gotoh, M. Kurihara and M. Sakamoto, Appl. Phys. Express, 2008, 1, 104002.

27 F. G. K. Baucke, Sol. Energy Mater., 1987, 16, 67-77.

28 A. Michaelis, H. Berneth, D. Haarer, S. Kostromine, R. Neigl and R. Schmidt, Adv. Mater., 2001, 13, 1825-1828.

29 D. Barrios, R. Vergaz, J. C. Torres-Zafra, C. Vega, J. M. SanchezPena and A. Vinuales, IEEE Photonics J., 2012, 4, 2105-2115.

30 J. Y. Lim, H. C. Ko and H. Lee, Synth. Met., 2005, 155, 595-598.

31 J. Padilla, V. Seshadri, G. A. Sotzing and T. F. Otero, Electrochem. Commun., 2007, 9, 1931-1935.
32 L. Rozanski, PhD thesis, University of Texas Austin, 2007, 76-78.

33 G. Sonmez, H. Meng and F. Wudl, Chem. Mater., 2004, 16, 574-580.

34 S. H. Hsiao and S. W. Lin, Polym. Chem., 2016, 7, 198-211. 35 C. W. Kuo, T. H. Hsieh, C. K. Hsieh, J. W. Liao and T. Y. Wu, J. Electrochem. Soc., 2014, 161, D782-D790.

36 S. Beaupre, A. C. Breton, J. Dumas and M. Leclerc, Chem. Mater., 2009, 21, 1504-1513.

37 S. Koyuncu, B. Gultekin, C. Zafer, H. Bilgili, M. Can, S. Demic, I. Kaya and S. Icli, Electrochim. Acta, 2009, 54, 5694-5702.

38 M. Sezgin, O. Ozay, S. Koyuncu, H. Ozay and F. B. Koyuncu, Chem. Eng. J., 2015, 274, 282-289.

39 W. Kaim and J. Fiedler, Chem. Soc. Rev., 2009, 38, 3373-3382.

40 R. J. Mortimer and J. R. Reynolds, J. Mater. Chem., 2005, 15, 2226-2233. 